\title{
DEVELOPING A HYBRID VALUE ENGINEERING AND RISK ASSESSMENT (VENRA) FRAMEWORK FOR SHIPBUILDING AND SHIP REPAIR INDUSTRY PERFORMANCE MEASUREMENT
}

\author{
I Baihaqi, I Lazakis, R E Kurt, Department of Naval Architecture, Ocean and Marine Engineering (NAOME), \\ University of Strathclyde, UK
}

\section{SUMMARY}

This paper proposes a novel performance measurement framework to enhance the decision-making process in assessing the ship manufacturing (shipbuilding, ship repair, and ship conversion/modification) industry. Integrated Value Engineering and Risk Assessment (VENRA) approach performance measurement for ship manufacturing is developed to tackle the problem. Thorough literature and critical study of the existing performance measurement for ship manufacturing are reviewed to create novel VENRA performance measurements. The attributes collected from the literature are grouped into four criteria performance, named VENRA attributes, combining the technical, business, external and safety/risk performance groups. The initial model will be assessed through fuzzy DEMATEL TOPSIS to achieve the weighted score of each attribute. The framework will be applied to three shipyard case studies in Indonesia. The quantitative data (from shipyards) and qualitative data (from expert opinion/judgment) will be included to get the results and the framework's effectiveness.

\section{INTRODUCTION}

Effective performance measurement seems to be the necessity to achieve more competitive industries. Regardless of its segment, sector, and size, a company cannot become competitive and sustainable unless it mainly accomplishes its value, quality, flexibility, and cost. It means selecting the proper criteria to model performance measurement remains a crucial matter. It shall assist the process of decision-making procedure. The critical factors in performance measurement should be selected to explain what companies should evaluate [1]. Ship manufacturing industries, including shipbuilding, ship repair and ship conversion, has unique technical and business factors. Technically, it consists of complex production processes, different technology levels, different building strategies, ship-type products and materials, and labours. In business view, it might be similar if compared with general sector industries; however, it has unique business knowledge in terms of finance, payment terms, bank involvement which should integrate with the technical knowledge. With this regard, the performance measurement to assess the competitiveness of ship manufacturing industries should have specific attributes/criteria.

The need for a universal measure of ship manufacturing industry performance has been recognised for many years. The Organisation for Economic and Co-operative Development (OECD) developed the concept of CGT (Compensated Gross Tonnage) as the global shipbuilding performance measurement. The basic principle is to take the gross tonnage (GT) and multiply it by a compensation factor that "corrects" the GT for differing work content [2]. The correction factors in CGT have changed to consider the changes in ship technology and production, which in this case, the 2007 version of CGT is the latest. CGT as the shipbuilding performance measurement has been developed with different approaches and corrections. Zhangpeng and Flynn [3] proposed a correction of CGT calculation by adding the productive shipyard area, while Bruce [4] proposed a new interpretation in applying the
CGT graph to be more helpful. Pires, Lamb and Souza [5] use Data Envelopment Analysis (DEA) and Analytical Hierarchy Process (AHP) for performance measurement benchmarking. Recent developments include [6], who proposed the Balanced Scorecard (BSC) model assessed through a hybrid MCDM approach.

This paper enriches the literature on ship manufacturing performance and competitiveness globally, specifically for Indonesian shipyards with different ship types. The contributions of this paper are as follows. First, it unfolds the ship manufacturing performance measurement methodology, including the key performance indicator collected, providing the gaps of the method used and the selected criteria. Secondly, it purposes VENRA (Value Engineering and Risk Assessment) model applied in selected indicator to assess ship manufacturing performance, combining the technical, business, external and safety/risk grouped attributes. Thirdly, it demonstrates a hybrid MCDM approach through Fuzzy DEMATEL TOPSIS through the VENRA attribute model, allowing practitioners to face complicated issues with multiple contradictory criteria. The model hypothesises that ship manufacturing performance measurement will be more enhanced through the VENRA model attributes assessed by the hybrid MCDM approach and can effectively measure technical, business, external and safety/risk attributes.

The structure of this paper is as follows. Section 1 reviews the development of ship manufacturing performance measurement methodology and the need to pursue enhanced performance indicators. Literature and critical review regarding performance measurement in ship manufacturing, value engineering and risk assessment, fuzzy Multi-Criteria Decision Making (MCDM) is presented in section 2. The VENRA model for performance measurement in shipbuilding assessed through the hybrid MCDM approach is delivered in section 3 . Section 4 discusses the case study plan for three shipyards in Indonesia, and section 5 concludes and provides further into future work. 
2.

2.1 SHIP MANUFACTURING PERFORMANCE MEASUREMENT INDICATORS

The conventional performance measurement in shipbuilding utilises Compensated Gross Tonnage (CGT) to compare one shipyard to other shipyards presented in CGT and cost curves. CGT can be defined as the amount of work necessary to build a given ship. It is measured by multiplying ship tonnage with coefficients, determined according to the type and size of a particular ship [2]. Some researchers utilise CGT in performance measurement in shipbuilding; others criticised the weakness and proposing a new way to represent the use of CGT. Bruce [4] proposed a new interpretation in CGT for shipbuilding performance by adding a correction in interpreting the CGT graph. Zhangpeng and Flynn [3] added the correction of CGT calculation by adding the productive shipyard area factor. Pires, Lamb, and Souza [5] propose a methodology for shipbuilding performance assessment by taking into account the characteristic of the shipyard, the production pattern and the industrial environment of the country region. A Data Envelopment Analysis (DEA) model is proposed to assess the shipyard performance, and an Analytical Hierarchy Process (AHP) method is used to obtain the Industrial environment indicator. Colin and Pinto [7] use several turnover measures, including main physical assets such as dock area, berth length, lifting capacity and the output CGT.

Fareza [8], in his Master Thesis, has developed shipbuilding performance measurement benchmarking using DEA, comparing major shipyards in Asia to acquire the market share by analysing the input and output. Chao and Yeh [9] comparing major shipyards' productivity in China, South Korea, and Japan using the DEA metafrontier framework. Gavalas, Syriopoulus and Tsatsaronis [6] proposed a performance measurement model to assess the shipbuilding industry's key performance indicators using a Balanced Scorecard (BSC) with the MCDM approach (Fuzzy DEMATEL, Fuzzy ANP, and MOORA). The application of BSC as the performance measurement has been broadly used in many sectors. However, in BSC, the dimension measured is limited to business process, internal process, learning and growth and customer satisfaction. Concerning the shipbuilding industry case, the attribute can be enhanced more by adding developing own attribute combining business, technical, external and risk/safety factors. In this case, the VENRA attribute model is proposed to tackle the performance measurement attributes gaps.

\subsection{VALUE ENGINEERING}

Value Engineering (VE) was first created and introduced by Lawrence D. Miles In 1947 named "Techniques of Value Analysis and Value Engineering" at General Electric due to material scarcity during World War [10]. The concept then adopted and implemented multidiscipline, including product design, construction project enhancement, and process enhancement. Society of American Value Engineers) (SAVE) define that VE is a systematic and structured approach for improving projects, products and processes. It analyses and improves manufacturing products and processes, design and construction projects, and business and administrative processes. It also helps achieve the optimum balance between function, performance, quality, safety, and cost, resulting in the maximum value for the project [11]. VE has broadly applied in many sectors and cases. It starts from the construction project, product development, performance-based and decision-making process.

VE is a systematic technical analysis method that targets the lowest lifecycle cost while achieving essential functions for product users. It commonly expresses as the ratio of function to cost [12]:

\section{Value $=($ Function $) /$ Cost}

The higher the value, the better the usage of the resources; likewise, a lower value indicates that resources are not efficiently used. There is still an opportunity to improve products or choices by either increasing the functionality or reducing the cost.

The recent paper discusses VE application in the construction project [13], combining the VE and constructability concept in the infrastructure project. Gunarathne et al. [14] propose a framework of integrated sustainability and VE concepts for construction projects, and [15] apply VE techniques in residential buildings. The primary approach used is through the VE-job plan, which uses multi-disciplinary team workshop based, analysing the existing data and purposing the new alternative approach to reduce the cost project without compromising the project quality and performance.

The VE concept is also widely broad applied in product development case studies. Alekseev, Kissin and Gorelov [16] studied the VE implementation for foam-cyclone cleaners by decomposing the product function and cost and altering the model into four options. The analysis includes the hydraulic resistance changes, design complexity, material consumption, dimensions, manufacturing complexity, assembly accuracy, and encrustation sensitivity. The expert evaluation performed the scoring. It shows that VE can help to improve product design while maintaining the techno-economic parameters. A similar approach was also studied by [17] on reducing product cost while maintaining customer satisfaction in global pumping unit production. It tries to change the rotor design as cast slots and reduce the pump body and stator housing weight. Silaskar and Shinde [18] performed the VE concept to find the weight optimisation of the ball valve used hydraulic system by changing the ball valve design and examining it through simulation software to check the tensile stress. Vijayan et al. [19] apply the VE concept to reduce the cost and weight of air suspension products by redesigning the product and analysing the stress and resultant displacement using simulation software. Kalluri and Kodali [20] have implemented VE methodology for hydraulic systems for agricultural and construction equipment by alternating the grade of materials, changing the manufacturing method, and finding possible alternative solutions. Integrated product development method based on VE and design for 
assembly concept has been proposed by [21], seeking the balance between value and cost of all functions of a mechanical subset. Based on the above review, the VE approach has been applied to improve product manufacturing through breakdown function and cost, then purposing the alternative options and involving the expert judgment or simulation software to score or verify the alternative options.

Despite the wide broadly of VE implementation in many sectors, the application of VE in the Marine sector is still few, especially in the shipbuilding or ship repair industry. Garratt [22] applied the VE concept to develop the 33 HP marine industrial engine part, while Tao, Yang and Shi [23] applied the cost control of marine diesel using the VE concept. Hyland [24] implemented the VE concept on designing the division of a large graving dock using slave caissons. Al-Yafei et al. [25] have developed offshore topside facilities manufacturing by alternate the materials using matrix value. VE has been implemented in shipbuilding cases by [26] utilising the ship design value stream. Romano et al. [27] and Formentini and Romano [28] discuss knowledge transfer based on value analysis in a shipbuilding project with the marine piping and electrical cable system case study. Tang and Bittner [29] developed a creative design solution for a marine construction project. The VE's concept has also been applied in ship hull construction by [30] on reducing the rework in the shipbuilding project using matrix and costbenefit function through the VE workshop. Karami and Olatunji [31] suggested that the marine project's key protocols should be applied to reduce cost and time while optimising the project's quality. From this literature review, the application of VE in shipbuilding and or ship repair is relatively few. It has not been formalised, especially in the shipbuilding and ship repair industries. In addition, the application of VE as the performance measurement is still few. Lee et al. [32] purpose the performance-based VE application to public highway construction. The project performance criteria are identified and weighted using the AHP method. Through the VE job plan, the alternatives scenario in the creative phase through Function Analysis System Technique (FAST) analysis is developed, and the performance is measured compared to the baseline. The project value is calculated based on performance over the cost in which the higher index has the best alternative / has improved value. Heralova [33] studied the possibility of using VE in a highway construction project. It analyses the possibility of using VE by extracting the benefits and conceiving them into the highway construction project. Anam et al. [34] adopted the [32] approach to implementing the water supply project with the same approach.

The application of VE for the decision-making process has also been widely applied with a combination of other methods. Karunasena and Rajagalgoda [35] examine the existing practices of $\mathrm{VE}$ techniques and propose to standardise VE practices with purposed decision-making formula to determine the profitability of VE applications before implementation. A coherent framework for utilising a VE approach to supply chain cost management and overcome the limitation utilising MCDM approach grey multi-criteria decision making presented by [36]. Zhao et al. [37] take the benefit concept of financial and functionality in VE to purpose VE-based facility decision making process by integrating with lifecycle cost analysis. The literature review about VE shows that:

VE application can be used in many case studies (product development, construction industry, decision-making and performance measurement)

- The point of VE implements the VE job plan (Information phase, function analysis, creative phase, development phase, implementation phase) and is followed by the decision-making process in the end.

- The main contribution of VE is that it has a concept on how to maintain value and quality and to reduce cost by investigating the function of project/ product/ equipment and provide an alternative to creating the best value for the decision-making process

- The main power also involves a multi-disciplinary team that can fill the knowledge gap of each other decision-makers.

- Many papers also adapt or modify the VE concept into other methods, models, MCDM decision-making tools, and others from the literature review. It shows that the VE can be integrated and modified into other tools to gain the concept's benefits.

\subsection{INTEGRATED VALUE ENGINEERING AND RISK ASSESSMENT (VENRA)}

The opportunity to integrate VE with formal risk assessment and analysis started in 1993 when a city port authority required a value engineering effort enhanced with a risk assessment application [12]. Other researchers also studied the method integration and explored the advantages. Mootanah [38] interfaced the integrated risk and value management methodologies theoretically and practically in construction project management. It reviews the evolution of value and risk management frameworks and explaining the basis for framework integration. AbdKarim [39] attempted to apply IRVM (Integrated Risk and Value Management) workshop to integrate risk management and value management qualitatively through four infrastructure projects in the UK. Ahmad et al. [40] explored the potential advantages of integrating RM and $\mathrm{VM}$ and the critical success factors (CSF) related to the implemented successfulness of the IRVM workshop. The case study was applied to the combined method following the standard of value management AS 4183:2007 and risk management AS/NZ 4360:2004. Feili et al. [41] used integrated risk management and VE to achieve an optimal approach in developing alternative energy renewable energy projects while reducing the cost and environmental pollution. Pedju and Mawu [42] identify and analyse factors related to the risks and value on the development of the construction projects through the design and engineering phase. The data are collected through questionnaires, interviews, and project's documentation. El Khatib [43] highlighted the concept of project risk management with VE in tendering process. Golabchi et 
al. [44] represented a model based on the combined VE and risk management to enhance the project cost management process in quantitative analysis of existing risks to improve the project's final cost. Sabzkohi and Pourrostam [45] used integrated VE and risk management method in exterior design project through optimised value index as a measure for decision-making process with clarifying the advantages and disadvantages.

The above literature focuses on integrating risk and value through project management, implemented in general project construction. The method used is primarily analytical; some researchers use quantitative risk analysis based on interviews from expert opinion. However, the integrated VE and risk assessment (VENRA) framework has not been implemented in shipbuilding and ship repair projects. The focus is more on value management, not on VE knowledge. In addition, the implementation of integrated VE and risk assessment has not been attempted for the performance measurement tool. The present paper will adopt the VE concept integrated with risk assessment into the VENRA model to be applied in performance measurement model attributes.

\subsection{FUZZY MULTI-CRITERIA DECISION MAKING (MCDM)}

In 1965, Zadeh [46] introduced Fuzzy Set Theory (FST) to accommodate the vagueness to answer the question. Since then, various researchers have developed the theory, including [47], who developed fuzzy set theory and its application through disjunction and conjunction. Moreover, Chen and Hwang [48] developed a fuzzy Multi Attributive Decision-Making (MADM) approach and [49] with Fuzzy logic in engineering applications.

FST has been broadly used to enhance the decisionmaking process in shipbuilding, ship repair and maintenance and the shipyard industry. Guneri et al. [50] and Sahin et al. [51] use a fuzzy AHP shipyard selection based on game theory. There is a broad application of FST in the case of the selection process, such as selecting the best maintenance approach [52], selecting the best propulsion/ manoeuvring system [53], supplier selection in the shipbuilding industry [54], shipping registry selection for existing ship or newly built ship [55], and shipyard facility layout selection [56]. In the performance measurement case, Chou and Liang [57] and Celik et al. [58] use fuzzy to evaluate performance evaluation in shipping companies and docking facilities, respectively. In addition, Freitas et al. [59] demonstrate a fuzzy model for the prioritisation analysis of variable quality performance in shipbuilding. Gayathri et al. [60] and Gavalas et al. [6] use fuzzy MCDM to study port operational and financial performance analysis and assess key performance indicators in the shipbuilding industry, respectively.

Some observations from the literature review concerning shipbuilding performance measurement are summarised as follows:

- The classical MCDM approaches have their benefits and drawback. The integration of the MCDM model can overcome the limitation of the individual approach and enhance the efficiency of the decision-making process. The combination of MCDM methods has received the most attention recently. However, to the best of the author's knowledge, no study integrates the MCDM technique of DEMATEL and TOPSIS to solve the performance measurement in the manufacturing industry. This study purposes a hybrid Fuzzy DEMATEL TOPSIS approach to determine the importance weights of decision-making criteria and evaluate the performance of different ship manufacturing industries.

- The review also shows that the criteria used are mainly on the business aspect. The technical aspect included is also in the general group, such as steel processing or shipyard facility or capacity. Some of the technical aspects can be derived in more detail to measure the performance measurement. In this study, the criteria are developed based on the VENRA approach by combining technical, business, external and safety/risk criteria, which is part of the VENRA approach.

- The study to model the performance measurement in ship manufacturing by using the MCDM approach is still few. Thus, the paper's contribution is to develop this model based on VENRA by using a novel Fuzzy DEMATEL TOPSIS approach in the ship manufacturing industry.

\section{METHODOLOGY}

\subsection{VENRA MODEL ATTRIBUTES}

The developing process of the model starts with collecting attributes related to shipbuilding performance measurement, ship repair, selecting the best docking facility, selecting the best shipyard of shipyard competitiveness in the literature review. The collected attributes were assessed through the VENRA approach by categorising the attributes into four groups: business, technical, external and risk/safety performance, as shown in Figure 1.

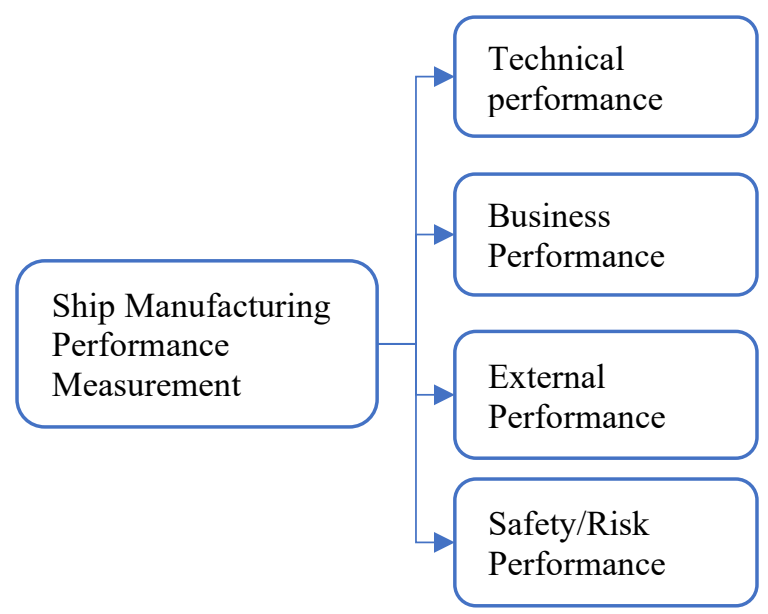

Figure 1. Group attribute for ship manufacturing performance measurement. 


\section{1 (a) Technical Group Performance}

It relates to technical things to production processes in ship manufacturing, starting from engineering production to delivery. This attribute group includes performance criteria indicators related to the shipyard capacity, building strategy, workforce, and technology level. The more detail of the technical group performance is as follow:

1. Shipyard Capacity

a. Total area

b. Erection area

c. Main Crain Capacity

2. Building Strategy (Panel, Block, Block Outfitting, Integrated Hull Outfitting Painting/IHOP)

3. Workforce

a. Worker Education level

b. Workforce Availability:

i. Worker availability

ii. Graduate availability

c. The average age of worker

4. Level of Technology

a. Fabrication and assembly

i. Steel Stockyard and treatment

ii. Cutting and marking

iii. Sub-assembly

iv. Flat panels

v. Assembling

b. Erection and Outfitting

i. Erection

ii. Outfitting

c. Product and processing engineering

i. Ship design (engineering design process)

ii. Production engineering (hardware \& software)

d. Layout, material flow, and environment

3.1 (b) Business Group Performance

The most important in business group performance is the cost and delivery time of the production process. in addition, shipyard experience and reputation will be included in this group and the organisation and management. The business group performance attribute in more detail is as follow:

1. Shipbuilding Cost

2. Delivery time (keel laying to delivery), more on-time delivery.

3. Shipyard experience building the same ship type on time.

4. Organisation and management (Organise the business process):

a. Marketing team availability

b. Human resources (HRD)

c. R\&D team availability
3.1 (c) External Group Performance

The ability to gain external resources is also very crucial to ship manufacturing performance. It includes vertical integration to gain suppliers, additional workers or equipment, government support and the domestic market. The detail of the external group performance is as follows:

1. Vertical integration (the ability to gain suppliers, additional workers or equipment)

2. Government support/subsidies. Bruce [61] suggests that the political environment play a vital role in international ship production, such as government support to the shipyard to maintain employability worker European shipyard due to the growth of Asia shipyard. However, it does not affect military ship construction, local ferries, fishing vessels, offshore support, tugs, and other service vessels that do not exist prominently in the international market.
a. Domestic market protection
b. Investment and research support
c. Direct production assistance
d. Export credit assistance
e. Assistance to customers such as tax breaks for shipowners
f. Home credit schemes
g. Favourable tax treatment

3. Domestic market.

4. Location environment

3.1 (d) Safety/Risk Group Performance

Activity in the shipyard to build or repair a ship is a hazardous activity. This safety/risk performance sometimes have not the priority in performance measurement. Thus the risk/safety group performance is also included to measure the safety operation of the shipbuilding process. It includes the safety of the workers, the environment, and the risk of product failure. In this case, the safety training induction and the availability of the OHSAS certificate will be included in the criteria. At the same time, the risk of the product will measure the probability of rework in the production process. The list of safety/risk group performance is as follows:

1. The availability of OHSAS certificate

2. Safety training induction

3. The risk of rework

\section{$3.2 \quad$ FUZZY DEMATEL}

The performance of shipbuilding depends on several factors that are either directly or indirectly related. Hence, evaluating ship manufacturing industry performance based on a single factor may not be justifiable. The DEMATEL method (Decision-Making Trial and Evaluation Laboratory) can be used to analyse the relationship amongst multiple complex factors. However, the evaluation criteria in this context may be imperfect or can contain uncertain factors, so the human judgement about preferences can be difficult to estimate by exact numerical values. 
The fuzzy DEMATEL method can help to overcome this and has been used by several researchers. This research uses a fuzzy DEMATEL approach to estimate the criteria weights. The relationship between the factors considered is evaluated based on the opinions of experts using a fuzzy scale. Table 1 shows the fuzzy scale mapping the degree of influence with the linguistic terms.

Table 1. linguistic terms for fuzzy DEMATEL evaluation

\begin{tabular}{|c|c|c|}
\hline Linguistic term & Abbreviation & Fuzzy scales \\
\hline None & N & $(0,0,1)$ \\
\hline Very Low & VL & $(0,0.1,0.2)$ \\
\hline Low & L & $(0.1,0.2,0.3)$ \\
\hline Fairly Low & FL & $(0.2,0.3,0.4)$ \\
\hline More or less low & ML & $(0.3,0.4,0.5)$ \\
\hline Medium & M & $(0.4,0.5,0.6)$ \\
\hline More or less good & MG & $(0.5,0.6,0.7)$ \\
\hline Fairly good & FG & $(0.6,0.7,0.8)$ \\
\hline Good & G & $(0.7,0.8,0.9)$ \\
\hline Very Good & VG & $(0.8,0.9,1)$ \\
\hline Excellent & E & $(0.9,1,1)$ \\
\hline
\end{tabular}

Step 1: Obtain a $n \times n$ fuzzy direct-relation matrix $\tilde{A}$ from experts, based on pairwise comparisons of the criteria. its elements $\tilde{a}_{i j}=\left(l_{i j}, m_{i j}\right.$, $\left.u_{i j}\right)$ represent the degree to which criterion $j$ is affected by criterion $i$.

Step 2: Determine the normalised fuzzy direct-relation matrix $\tilde{X}$ using equation (1).

$$
\tilde{X}=s \times \tilde{A}
$$

$$
\text { Where } s=\frac{1}{\max 1 \leq i \leq n \sum_{j}^{n} U_{i j}}
$$

Step 3: Define three crisp matrices based on $\tilde{X}$, where $\tilde{x}_{i j}$ $=\left(l_{i j}, m_{i j}, u_{i j}\right)$.

$X_{l}=\left[\begin{array}{cccc}0 & l_{12} & \ldots & l_{1 n} \\ l_{21} & 0 & \ldots & l_{2 n} \\ \vdots & & & \vdots \\ l_{n 1} & l_{n 2} & \ldots & 0\end{array}\right], X_{m}=\left[\begin{array}{cccc}0 & m_{12} & \ldots & m_{1 n} \\ m_{21} & 0 & \ldots & m_{2 n} \\ \vdots & & & \vdots \\ m_{n 1} & m_{n 2} & \ldots & 0\end{array}\right]$,

$X_{u}=\left[\begin{array}{cccc}0 & u_{12} & \ldots & u_{1 n} \\ u_{21} & 0 & \ldots & u_{2 n} \\ \vdots & & & \vdots \\ u_{n 1} & u_{n 2} & \ldots & 0\end{array}\right]$

Step 4: Obtain the fuzzy total-relation matrix $\tilde{T}$ using equations (2) to (5).

$\tilde{T}=\tilde{X}(I-\tilde{X})^{-1}$

$\operatorname{Matrix}\left[l_{i j}^{\prime}\right]=X_{l}\left(I-X_{l}\right)^{-1}$

$\operatorname{Matrix}\left[m^{\prime}{ }_{i j}\right]=X_{m}\left(I-X_{m}\right)^{-1}$

$\operatorname{Matrix}\left[u_{i j}^{\prime}\right]=X_{u}\left(I-X_{u}\right)^{-1}$

$\tilde{T}=\left[\begin{array}{cccc}\tilde{t}_{11} & \tilde{t}_{12} & \ldots & \tilde{t}_{1 n} \\ \tilde{t}_{21} & \tilde{t}_{22} & \ldots & \tilde{t}_{2 n} \\ \vdots & & & \vdots \\ \tilde{t}_{n 1} & \tilde{t}_{n 2} & \ldots & \tilde{t}_{n n}\end{array}\right]$ where, $\tilde{t}_{i j}=\left(l_{i j}^{\prime}, m_{i j,}^{\prime}, u_{i j,}^{\prime}\right)$

and $I$ is the identity matrix.
Step 5: Defuzzify $\widetilde{T}$ using equation (6) and determine the total influence matrix for each set of sub-criteria considered.

$F\left(\tilde{t}_{i j}\right)=\frac{1}{2} \int_{0}^{1}\left(\inf _{x \in \mathcal{R}} \tilde{t}_{i j}^{\alpha}+\sup _{x \in \mathcal{R}} \tilde{t}_{i j}^{\alpha}\right) d \alpha$

Step 6: compute the row sum $(r)$ and the total influence matrix's column sum (c). $r+c$ gives the degree to which factor $i$ affects or is affected by $j$. A positive value of $r-c$ means that factor $i$ affects other factors and vice versa if it is negative [62].

Step 7: Determine the weights by normalising the $r+c$ values.

\subsection{TOPSIS}

The technique for order of preference by similarity to ideal solution (TOPSIS) assumes that any chosen alternative should be closer to the positive ideal solution and far away from the negative ideal solution. TOPSIS has the following steps [62]:

Step 1: Obtain the decision matrix $D$ for evaluation with elements $f_{i j}$, based on the various criteria considered.

Step 2: Determine the normalised decision matrix with elements $r_{i j}$

$$
r_{i j}=\frac{f_{i j}}{\sqrt{\sum_{j} f_{i j}^{2}}}
$$

Step 3: Calculate the weighted normalised decision matrix with elements $v_{i j}$ using the weight $w_{i}$ for each criterion.

$$
v_{i j}=w_{i} \cdot r_{i j}
$$

Step 4: Find the ideal and negative-ideal solution using equation (9) and (10), where $I$ ' is the set of benefit criteria, and $I^{\prime \prime}$ is the set of cost criteria.

$$
\begin{aligned}
& A^{+}=\left\{v_{1}^{+}, \ldots, v_{n}^{+}\right\}=\left\{\left(\max _{i j} \mid i \in I^{\prime}\right),\left(\operatorname{minv}_{i j} \mid i \in I^{\prime \prime}\right)\right\} \\
& A^{-}=\left\{v_{1}^{-}, \ldots, v_{n}^{-}\right\}=\left\{\left(\operatorname{mix}_{i j} \mid i \in I^{\prime}\right),\left(\max _{i j} \mid i \in I^{\prime \prime}\right)\right\}
\end{aligned}
$$

Step 5: Determine the distance from the positive ideal solution $D_{j}^{+}$and the distance from the negative-ideal solution $D_{j}^{-}$for each alternative $j$.

$$
\begin{aligned}
& D_{j}^{+}=\sqrt{\sum_{i}\left(v_{i j}-v_{i}^{+}\right)^{2}} \\
& D_{j}^{-}=\sqrt{\sum_{i}\left(v_{i j}-v_{i}^{-}\right)^{2}}
\end{aligned}
$$

Step 6: Evaluate the relative closeness to the ideal solution for each alternative $j$ and rank the alternatives.

$$
C_{j}^{*}=\frac{D_{j}^{-}}{\left(D_{j}^{+}+D_{j}^{-}\right)}
$$

The global framework of VENRA through MCDM approach is shown in Figure 2. 


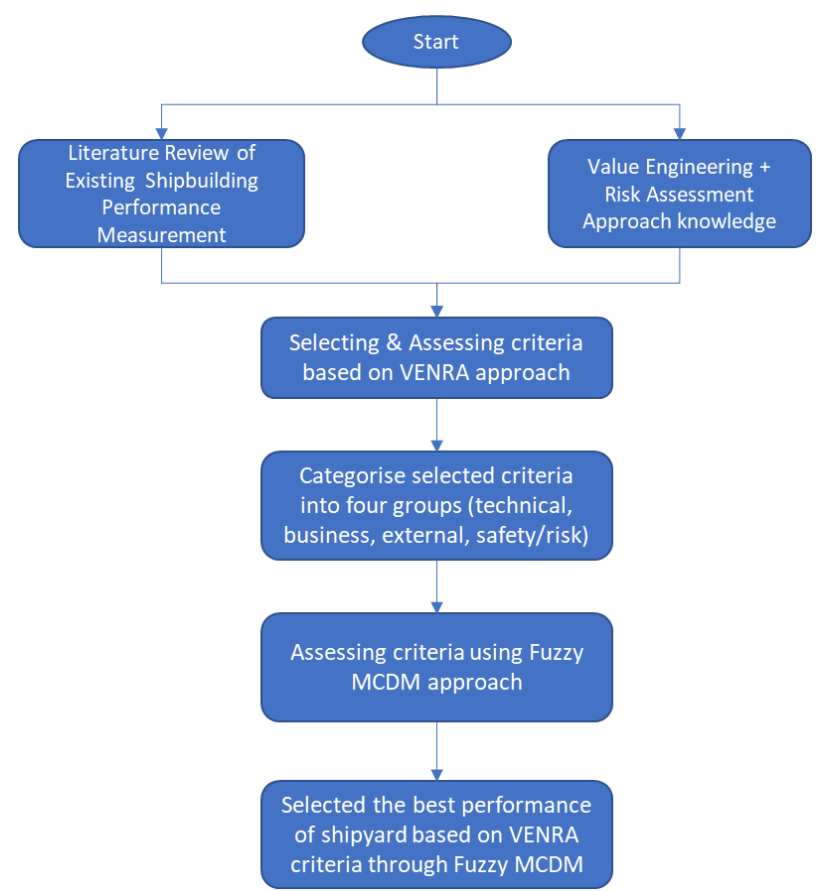

Figure 2. Methodology of VENRA performance measurement for ship manufacturing.

\section{DISCUSSION \& CASE STUDY PLAN}

This model will be used to examine the performance measurement for three shipyards in Indonesia, located in Java island and Madura Island, as shown in Figure 3.

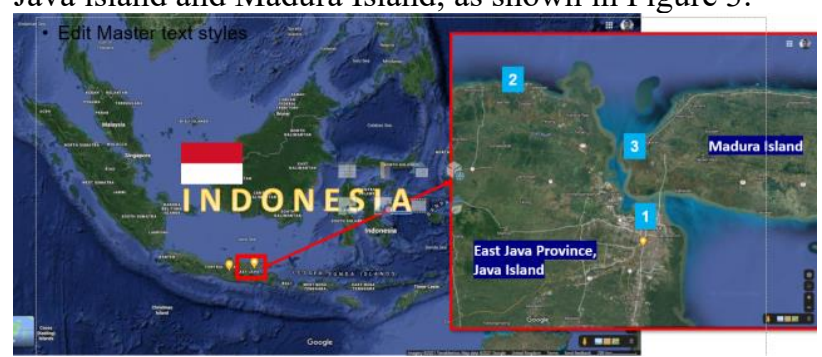

Figure 3. Location of the shipyards

The first shipyard is a state-owned shipyard that has a high level of technology and organisation. With a crane of 300 tons and graving docks up to 200 meters, this shipyard can produce mix products, including shipbuilding, ship repair, and offshore repair facilities. It is one of the shipyards that have high technology and product quality.

The second shipyard is a private shipyard that has a small area with outstanding human resources and a research and development team. They have experience in building IACS class ships such as harbour tugs. It also has flexibility in design and team.

The third shipyard is located in Madura Island, and it is a private shipyard. They have a large green area that has not been developed yet. Initially, they focused on ship repair for their own group shipping company. Then, they are developing the shipbuilding also for ferry, general cargo owned by the Indonesian government and ordered from their own group shipping company. In general, this shipyard has an excellent opportunity to involve tender in the domestic market. The overview of the shipyard as the case study is shown in Figure 4, respectively, with the explanation above.
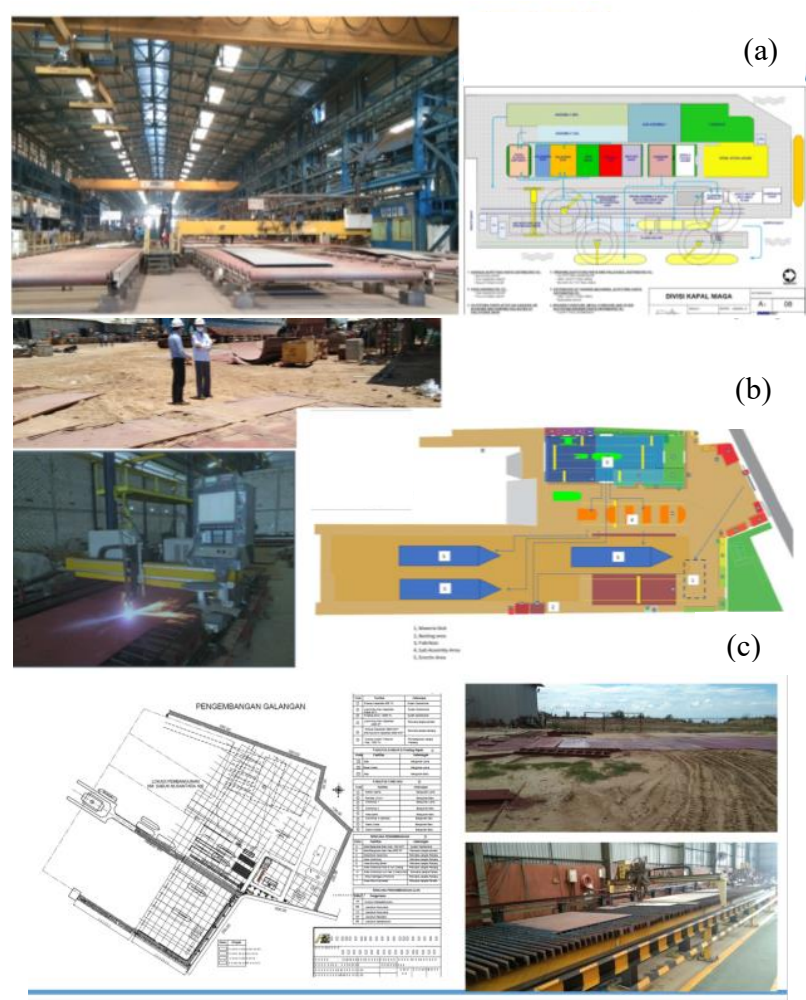

Figure 4. Shipyards case study, the first (a), the second (b), and the third (c).

\section{CONCLUSION \& FUTURE PLAN}

VENRA model approach has been purposed as criteria for ship manufacturing performance measurement, combining the technical, business and external value and risk/safety aspect. The criteria assessment is still limited to the literature review and unstructured interviews with expertise by shipping and shipyard companies. The fuzzy MCDM approach can be enhanced by studying the benefits and the drawbacks of using Fuzzy MCDM for performance measurement and comparing it with other methods.

Moreover, as the work presented in this paper is ongoing, further research will include updating and developing the criteria mentioned above, including feedback and validation by industry experts working in the shipbuilding and ship repair industry. In addition, data related to the mentioned case studies and shipyards will be collected through a number of sources i.e. annual reports, experts' interviews, and other supporting material by the existing literature.

\section{ACKNOWLEDGEMENT}

The author sincerely wants to thank the Directorate General of Recourses for Science Technology and Higher Education as BPP-LN "Beasiswa Pendidikan Pascasarjana Luar Negeri", the funding body scholar to pursue a PhD Researcher in the University of Strathclyde, the United Kingdom. 


\section{REFERENCES}

[1] J. L. Harbour, The Basics of Performance Measurement, vol. 21, no. 2. 1999.

[2] OECD, "Compensated Gross Ton (CGT) System," 2007.

[3] G. Zhangpeng and M. Flynn, "Productive shipyards," LLoyds Shipp. Econ., pp. 37-38, 2006.

[4] G. J. Bruce, "A review of the use of CGT for shipbuilding performance measurement," 2005 SNAME Marit. Technol. Conf. Expo Sh. Prod. Symp., vol. 22, no. 2, pp. 99-104, 2006.

[5] J. F. Pires, T. Lamb, and C. Souza, "Shipbuilding performance benchmarking," Int. J. Bus. Perform. Manag., vol. 11, no. 3, pp. 216-235, 2009.

[6] D. Gavalas, T. Syriopoulos, and M. Tsatsaronis, "Assessing key performance indicators in the shipbuilding industry; an MCDM approach," Marit. Policy Manag., vol. 00, no. 00, pp. 1-29, 2021.

[7] E. C. Colin and M. M. O. Pinto, "Benchmarking shipbuilders' turnover of main assets," J. Sh. Prod., vol. 25, no. 4, pp. 175-181, 2009.

[8] M. Fareza, "Study of Shipbuilding Competitiveness - Benchmarking analysis as a tool to measure shipyards' competitiveness with a focus on Asian yards," 2020.

[9] S. L. Chao and Y. H. Yeh, "Comparing the productivity of major shipyards in China, South Korea, and Japan - an application of a metafrontier framework," Marit. Bus. Rev., vol. 5, no. 2, pp. 193-210, 2020.

[10] L. D. Miles, Techniques of Value Analysis and Engineering, Third Edit. USA: Eleanor Miles Walker, Lawrence D. Miles Value Foundation, 1989.

[11] SAVE International, "Value Standard and Body of Knowledge," 2007.

[12] A. Dell'Isola, Value Engineering: Practical Applications for Design, Construction, Maintenance \& Operation. Kingston - USA: R.S. Means Company, Inc, 1997.

[13] S. K. I. Al-Fadhli, "Value Engineering and Constructability Assessment Relating Infrastructure Projects," in IOP Conference Series: Materials Science and Engineering, 2020, vol. 737, no. 1 .

[14] A. S. Gunarathne, N. Zainudeen, C. S. R. Perera, and B. A. K. S. Perera, "A framework of an integrated sustainability and value engineering concepts for construction projects," Int. J. Constr. Manag., vol. 0, no. 0, pp. 1-13, 2020.

[15] F. John, A. Reji, A. Vincent, B. Biju, and S. Kuriakose, "Application of Value Engineering Techniques in Residential Building," Int. J. Res. Appl. Sci. Eng. Technol., vol. 9, no. 5, pp. 11931195, 2020.

[16] N. I. Alekseev, D. A. Kissin, and V. E. Gorelov, "Design improvements in foam-cyclone cleaners by the value engineering method," Chem. Pet. Eng., no. 24, pp. 187-191, 1988.

[17] A. Bhosle, A. Sah, and D. K. Shinde, "Application of Value Analysis and Value Engineering for Cost Reduction of Global Pumping Unit," in Advances in Simulation, Product Design and Development. Lecture Notes on Multi-disciplinary Industrial Engineering, 2020, pp. 663-674.

[18] S. M. Silaskar and V. B. Shinde, "Weight Optimization of Valve for Cost Effectiveness: Using Value Analysis," in Procedia Manufacturing, 2018, vol. 20, pp. 329-337.

[19] R. Vijayan, T. Thanka Geetha, B. Nishanth, M. Tamilarasan, and V. Vijaya Kumar, "Value engineering and value analysis of rear air spring bracket," in Materials Today: Proceedings, 2019, vol. 16, pp. 1075-1082.

[20] V. Kalluri and R. Kodali, "Component Cost Reduction by Value Engineering: A Case Study," J. Inst. Eng. Ser. C, vol. 98, no. 2, pp. 219-226, 2017.

[21] P. H. P. Setti, O. Canciglieri Junior, and C. C. A. Estorilio, "Integrated product development method based on Value Engineering and design for assembly concepts," J. Ind. Inf. Integr., vol. 21, no. December 2020, p. 100199, 2021.

[22] Garratt G, "Savings from The Use of Value Analysis," Machy (Lond), vol. 115, no. 2972, pp. 682-687, 1969.

[23] Y. H. Tao, J. Yang, and J. Shi, "Cost control of the marine diesel based on value engineering," Appl. Mech. Mater., vol. 551, pp. 535-540, 2014.

[24] H. L. Hyland, "Value analysis applied to the optimum division of a large graving dock using a slave caisson," J. Sh. Prod., vol. 7, no. 2, pp. 6976, 1991.

[25] E. Al-Yafei, S. Ogunlana, and A. Oyegoke, "Application of value engineering and life cycle costing techniques for offshore topside facility projects: Towards sustainability," Soc. Pet. Eng. SPE Kuwait Oil Gas Show Conf. 2017, 2017.

[26] R. L. Storch and M. Williamson, "Technology value analysis of the ship contract design value stream," IFIP Adv. Inf. Commun. Technol., vol. 129, pp. 147-158, 2003.

[27] P. Romano, M. Formentini, C. Bandera, and M. Tomasella, "Value analysis as a decision support tool in cruise ship design," Int. J. Prod. Res., vol. 48, no. 23, pp. 6939-6958, 2010.

[28] M. Formentini and P. Romano, "Using value analysis to support knowledge transfer in the multiproject setting," Int. J. Prod. Econ., vol. 131, no. 2, pp. 545-560, 2011.

[29] P. Tang and R. B. Bittner, "Use of value engineering to develop creative design solutions for marine construction projects," Pract. Period. Struct. Des. Constr., vol. 19, no. 1, pp. 129-136, 2014.

[30] T. N. Desai, S. R. Prajapati, and H. R. Patel, "Application of Value Engineering to Rework 
Reduction in Shipbuilding Project," in MATEC Web of Conferences 40, 2016, no. 2, pp. 17-45.

[31] H. Karami and O. A. Olatunji, "Key value engineering protocols in marine projects," Proc. Inst. Civ. Eng. - Manag. Procure. Law, vol. Vol. 173, no. 1, pp. 21-31, 2020.

[32] M. J. Lee, J. K. Lim, and G. Hunter, "Performancebased value engineering application to public highway construction," KSCE J. Civ. Eng., vol. 14, no. 3, pp. 261-271, 2010.

[33] R. S. Heralova, "Possibility of Using Value Engineering in Highway Projects," in Creative Construction Conference, 2016, vol. 164, no. June, pp. 362-367.

[34] S. Anam, E. Pradjoko, and B. Anshari, "Analysis of infrastructures design at mandalika resort project by using the value engineering," Int. J. Civ. Eng. Technol., vol. 9, no. 5, pp. 626-633, 2018.

[35] G. Karunasena and K. Rajagalgoda Gamage, "A decision-making formula for value engineering applications in the Sri Lankan construction industry," J. Financ. Manag. Prop. Constr., vol. 22, no. 1, pp. 77-91, 2017.

[36] J. Heidary Dahooie, S. J. Hosseini Dehshiri, A. Banaitis, and A. Binkytè-Vèlienè, "Identifying and prioritising cost reduction solutions in the supply chain by integrating value engineering and gray multi-criteria decision-making," Technol. Econ. Dev. Econ., vol. 26, no. 6, pp. 1311-1338, 2020.

[37] C. Zhao, E. Yang, Y. Nie, and J. D. Russo, "Facility decision making process with modified value engineering approach," J. Corp. Real Estate, vol. 21, no. 2, pp. 112-129, 2019.

[38] D. P. Mootanah, "Developing an integrated risk and value management framework for construction project management," in 14th Annual ARCOM Conference, 9-11 September 1998, University of Reading. Association of Researchers in Construction Management, 1998, vol. 2, no. 4, pp. 48-53.

[39] S. B. Abd-Karim, D. J. Lowe, H. Abdul-Rahman, C. Wang, I. A. Yahya, and G. Q. Shen, "Integrating risk and value management using IRVM workshops: Case studies in infrastructure projects in UK," Sci. Res. Essays, vol. 6, no. 12, pp. 24702479, 2011.

[40] R. Ahmed, B. John, and C. Nicholas, "Integration of risk management and value management - An Australian case study," Proc. Int. Conf. Value Eng. Manag. Innov. Value Methodol. ICVEM 2012, no. Vm, pp. 23-28, 2012.

[41] H. R. Feili, S. Nasiri, and N. Akar, "Integrating Risk Management and Value Engineering in the Development of Renewable Energy Project," in 6th Symposium on Advances in Science and Technology, 2012, pp. 1-10.

[42] M. Pedju and E. Mawu, "Considering the integrated value engineering and risk management techniques during the design phase in construction projects - its implications to project objectives (A
Case Study on Certain Irrigation Projects, North Sulawesi Province)," J. Ilm. Media Eng., vol. 3, no. 3, pp. 214-226, 2013.

[43] D. M. M. El Khatib, "Integrating Project Risk Management and Value Engineering in Tendering Processes," Int. J. Eng. Res., vol. 4, no. 8, pp. 442445, 2015.

[44] M. Golabchi, H. Toosi, and P. Shahsavand, "Quantitative Risk Analysis and Integration of Value Engineering to Increase the Efficiency of Project Management Case Study: Sattar Khan Commercial Centre - Flour Parking - Tehran," Mediterr. J. Soc. Sci., vol. 7, no. 4, 2016.

[45] B. A. Sabzkohi and T. Pourrostam, "Integrated Model of Value Engineering and Risk Management Approaches in Empowerment Projects ( the Exterior Design )," Int. J. Adv. Manuf. Technol., vol. 3, no. 3, pp. 52-56, 2016.

[46] L. A. Zadeh, "Fuzzy sets," Inf. Control, vol. 8, no. 3, pp. 338-353, 1965.

[47] H.-J. (Hans-J. Zimmermann, Fuzzy set theory--and its applications, 2nd rev. e. Boston: Kluwer Academic Publishers, 1991

[48] S.-J. Chen and C.-L. Hwang, "Fuzzy Multiple Attribute Decision Making Methods," in Fuzzy Multiple Attribute Decision Making: Methods and Applications, Berlin, Heidelberg: Springer Berlin Heidelberg, 1992, pp. 289-486.

[49] T. J. Ross, Fuzzy logic with engineering applications, 3rd ed.. Chichester, U.K.: John Wiley, 2010.

[50] A. F. Guneri, M. Cengiz, and S. Seker, "A fuzzy ANP approach to shipyard location selection," Expert Syst. Appl., vol. 36, no. 4, pp. 7992-7999, 2009.

[51] B. Sahin, D. Yazir, A. Soylu, and T. L. Yip, "Improved fuzzy AHP based game-theoretic model for shipyard selection," Ocean Eng., vol. 233, no. April, p. 109060, 2021.

[52] I. Lazakis and A. Ölçer, "Selection of the best maintenance approach in the maritime industry under fuzzy multiple attributive group decisionmaking environment," Proc. Inst. Mech. Eng. Part M J. Eng. Marit. Environ., vol. 230, no. 2, pp. 297 309, 2016.

[53] A. I. Ölçer and A. Y. Odabaşi, "A new fuzzy multiple attributive group decision making methodology and its application to propulsion/manoeuvring system selection problem," Eur. J. Oper. Res., vol. 166, no. 1 SPEC. ISS., pp. 93-114, 2005.

[54] X. Ziquan, Y. Jiaqi, M. H. Naseem, X. Zuquan, and L. Xueheng, "Supplier Selection of Shipbuilding Enterprises Based on Intuitionistic Fuzzy Multicriteria Decision," Math. Probl. Eng., vol. 2021, 2021.

[55] M. Celik, I. Deha Er, and A. F. Ozok, "Application of fuzzy extended AHP methodology on shipping registry selection: The case of Turkish maritime 
industry," Expert Syst. Appl., vol. 36, no. 1, pp. 190-198, 2009.

[56] V. Dixit, P. Verma, and P. Raj, "Leveraging tacit knowledge for shipyard facility layout selection using fuzzy set theory," Expert Syst. Appl., vol. 158, p. 113423, 2020.

[57] T.-Y. Chou and G.-S. Liang, "Application of a fuzzy multi-criteria decision-making model for shipping company performance evaluation," Marit. Policy Manag., vol. 28, no. 4, pp. 375-392, 2001.

[58] M. Celik, C. Kahraman, S. Cebi, and I. D. Er, "Fuzzy axiomatic design-based performance evaluation model for docking facilities in shipbuilding industry: The case of Turkish shipyards," Expert Syst. Appl., vol. 36, no. 1, pp. 599-615, 2009.

[59] P. de J. Freitas Pinto, C. H. dos Santos Grecco, and C. A. Nunes Cosenza, "Fuzzy Model for the Priorization Analysis of Variable Quality Performance: An Approach in Shipbuilding," Fuzzy Inf. Eng., vol. 12, no. 2, pp. 181-203, 2020.

[60] C. Gayathri, V. Kamala, M. S. Gajanand, and S. Yamini, "Analysis of operational and financial performance of ports: an integrated fuzzy DEMATEL-TOPSIS approach," Benchmarking An Int. J., vol. ahead-of-p, no. ahead-of-print, Jan. 2021.

[61] G. Bruce, "Competitiveness," in Shipbuilding Management, 2021, pp. 23-32.

[62] J. K. Chen and I. S. Chen, "Using a novel conjunctive MCDM approach based on DEMATEL, fuzzy ANP, and TOPSIS as an innovation support system for Taiwanese higher education," Expert Syst. Appl., vol. 37, no. 3, pp. 1981-1990, 2010.

\section{AUTHORS BIOGRAPHY}

Imam Baihaqi is currently a $\mathrm{PhD}$ Researcher at the Department of Naval Architecture, Ocean, and Marine Engineering, University of Strathclyde, United Kingdom. His research interests include shipbuilding manufacturing and productivity, risk analysis in shipbuilding, and marine material experiment. At the same time, he is the lecturer at the Department of Naval Architecture and Shipbuilding Engineering, Faculty of Marine Technology, in Institut Teknologi Sepuluh Nopember, Surabaya, Indonesia.

Dr. Iraklis Lazakis, Reader, CEng, MBA, FRINA, FSNAME, FHEA, PhD is a Reader at the Department of Naval Architecture, Ocean, and Marine Engineering at the University of Strathclyde. He has extensive academic and industry experience working in UK and EU research and marine industry projects. His research interests include ship systems condition monitoring, systems maintenance and reliability, ship operations, risk analysis, shipyard manufacturing and productivity, and asset management. $\mathrm{He}$ is currently the Chair in the ISSC Committee V.7 Structural longevity

Dr Rafet Emek Kurt, has principal research interests lie in the field of human factors in the maritime domain. He has investigated the effects of noise and vibration on human performance and developed a human response model for noise and vibration levels on-board ships. His research interests also include design, optimisation, operation of ships, by considering the human factors in the core of the subject. Besides his main research area, he has also been actively working in the area of ship recycling. For 8 years he has been working in this area and contributed the development of tools, models and training tailored for the unique needs of the ship recycling sector. $\mathrm{He}$ is also involved in following EU funded ship recycling projects; FP7 DIVEST Project, LLP Ship DIGEST Project and LLP Boat DIGEST Project. He is also actively attending IMO MSC and MEPC Meetings. 